\title{
PHARMACEUTICAL PRICING POLICY AND CONTROL: INDIAN PERSPECTIVE
}

\author{
RENGANATHAN R*, VIJAYABANU C, SRINIVASAKUMAR V, VIJAY ANAND V
}

School of Management, Sastra University, Thanjavur, Tamil Nadu, India. Email: renganathan@mba.sastra.edu

Received: 03 August 2016, Revised and Accepted: 12 August 2016

\begin{abstract}
Objective: Pharmaceutical sector is playing a key role toward the wellness of the people and economic development of India. The innovation, development, production, and marketing of medicines are accountable to the pharmaceutical industry. It is the duty of the government to ensure the availability of the lifesaving drugs at reasonable prices by means of considering the interest of both the producers and the buyers. To safeguard the public health, the National Pharmaceutical Pricing Authority (NPPA) is the watchdog in India, which controls the prices of drugs. The main objective of this study is to ascertain the various roles played by the NPPA, to control the prices of the drugs in India.
\end{abstract}

Methods: Data and information about "Revenue of Indian Pharmaceutical Sector," Pharmaceutical and Healthcare Industry in India, NPPA, and Drug Price Control Order (DPCO) were collected and used for this study. This study is based on the information from various secondary sources.

Results: In India, prices of the medicines are controlled, and price maximum for the essential medicines are set by the Indian government using DPCO. List of drugs in the National List of Essential Medicines (NLEM) is expanded. In India, NPPA controls the prices of NLEM and also controls the price increases of non-essential medicines.

Conclusion: Pharmaceutical companies can think of reducing the expenses to reduce the cost of drugs to comply with the government drug pricing policy. To ensure the affordability of medicines along with the pricing policy, the Indian government may look and concentrate on the other important areas of pharmaceutical sectors.

Keywords: Pharmaceutical sector, Price, Drugs, Regulator, National pharmaceutical pricing authority, Drug price control order.

(C) 2016 The Authors. Published by Innovare Academic Sciences Pvt Ltd. This is an open access article under the CC BY license (http://creativecommons org/licenses/by/4. 0/) DOI: http://dx.doi.org/10.22159/ajpcr.2016.v9i6.14461

\section{INTRODUCTION}

Price is one of the important marketing mix elements along with product, physical distribution, and promotion. It is obvious that price fetches revenue to organizations. When organization fixes price for its product, they have to keep their pricing objectives in their mind. By and large customers tend to associate quality with the price of any product. According to Philip Kotler, before selling the product through price, marketers have to sell the price. This may not be exactly applicable and extended to pharmaceutical products. The government is responsible for ensuring the availability of drugs, especially lifesaving at affordable price apart from meeting the interest of producers of pharmaceutical products.

As per the report of Indian Brand Equity Foundation (IBEF, 2016), from US $\$ 6$ billion in the year 2005, the Indian pharmaceuticals market improved at a CAGR of $17.46 \%$ in 2015 . Indian pharmaceuticals market is anticipated to develop at a CAGR of $15.92 \%$ to US\$ 55 billion by 2020 . Revenue of Indian Pharmaceutical Sector is given in Fig. 1. In Indian pharmaceutical sector, generic drugs have $70 \%$ of market share in terms of revenue and of total market revenues of US\$ 20 billion, over the counter medicines (OTC) and patented drugs comprise of $21 \%$ and 9\%, respectively (IBEF 2016) [1]. Revenue of Indian Pharmaceutical sector is given in Figure 1.

While setting the price for any product factors such as cost of production, cost of distribution, offering of the competitor, positioning strategy, and target customer have to be considered (April Maguire, 2015) [2]. To bring down the expenses of healthcare, the Government of India is taking a lot of initiative. The pharmaceutical market in India with Rs. 98,000 crore worth may face some problems because of the
Government of India regulatory policy like banning of some drugs, controlling prices, and withdrawing tax benefits (Rajagopal, 2016) [3]. According to Scangos, prices of the medicines will be fixed as per the value they fetch to patients and innovative drugs which make a difference in the lives of patients continue to acquire good pricing, Eric Fry, 2015 [4]. Revenue share of Indian pharmaceutical sub-segments in 2015 is given in Figure 2.

\section{Pharmaceutical and healthcare industry in India}

In India, healthcare is one of the major sectors from the perspective of revenue and employment which includes hospitals, medical devices, clinical trials, telemedicine, medical equipment, health insurance, medical tourism, and outsourcing (IBEF, 2015) [5]. Hospitals, nursing homes and diagnostics centers, and pharmaceuticals constitute $65 \%$ of the overall market come under healthcare delivery (IBEF, 2015) [5] To promote healthcare industry, the Government of India decided to open 3,000 medical stores across the country to offer quality medicines at reasonable prices (IBEF, 2015) [5]. By 2020, the Indian healthcare market is anticipated to develop to US\$280 billion from the current worth of US\$ 100 billion (IBEF, 2015) [5]. Due to rising consumer spending, rapid urbanization, and increasing healthcare insurance among others, by 2025, the Indian pharmaceutical sector is expected to develop to US\$100 (IBEF, 2016) [6]. Moreover, cost of production of pharmaceutical sector in India is considerably lesser than that of the US and almost half of that of Europe (IBEF 2016) [7]. As far as the global pharmaceuticals sector is concerned, India enjoys a significant position. The pharmaceutical market as the industry is highly fragmented in India which needs to be consolidated. The government has to control the price of essential lifesaving drugs affordable to all section of the society. At the same time, the government has to safeguard the interest 
and welfare of the drug manufacturers in India. According to industry officials, the Government of India's recent policy measure such as banning some drugs, controlling prices and withdrawing tax benefits with regard to pharmaceutical sector may affect the growth of Rs.98,000 crore pharmaceutical market, negatively affect the consolidation and Make in India Initiative, Rajagopal, (2016). According to Ms. Menghaney, Intellectual Property Right policy in India fails to acknowledge that IP is a market-driven model with regard to drugs for neglected disease, and there will be severe obstructions to access to drugs with this approach, Krishnan, 2016 [8].

If the medicine is deemed unaffordable, among other conditions, under the Indian Patents Act, a compulsory licensing (CL) can be issued for a drug, and the government grants permission to qualified generic drug makers to manufacture it. With regard to CL, India has issued only for a cancer drug (l) [9].

\section{National Pharmaceutical Pricing Authority (NPPA)}

Through the Government of India Resolution on August 29, 1997, The NPPA was established, and NPPA is responsible for the implementation of the National Pharmaceutical Pricing Policy, 2012 and the drugs prices control order (DPCO), 2013, Bhupendra Singh, Chairman, NPPA. NPPA safeguard the interest of producers and consumers by means of ensuring the sufficient availability lifesaving drugs at affordable prices [10]. Prices of any products can be based on cost and demand and supply of any product in general. As different to cost-based mechanism under DPCO 1995, market-based pricing mechanism was provided by DPCO 2013. As on June 10, 2016, NPPA fixed and notified the ceiling price of 330 formulations from the medicines in National List of Essential Medicines (NLEM)-2015 NLEM. As per NPPA Chairman Shri. Singh, IAS message, 969 scheduled formulations are under direct price control, as on date. It is the duty and responsibility of the government to ensure the availability of especially lifesaving medicines at affordable prices. According to the chairman, "the primary aim of the NPPA is to ensure adequate availability of essential and lifesaving drugs at affordable prices and in doing so, it carefully balances the interests of both the producers and the consumers." NPPA cuts the prices of the drugs used for the treatment of diseases such as cancer, diabetes, and BP by about $25 \%$ and also increased the prices of intravenous injection fluids such as glucose and sodium chloride (The Hindu, June 7, 2016. p. 15). Because of the price limit declared by NPPA, products of the major pharma firms in India will be affected (The Hindu, June 7, 2016. p. 15). In general, firms selling price depends on average costs and the customer's perceived value of the product in comparison to his or her perceived value of the competing products [11].

To review the DPCO 2013, Government of India formed an inter-ministerial committee, following the Supreme Court verdict that termed the drug pricing policy as irrational and unreasonable [12].

Because the complaints about pharma companies making enormous profit, the inter-ministerial committee would look into the drug pricing mechanism [12]. The Supreme Court had observed that the Center was fixing maximum price of a medicine above the retail price of the leading company while hearing the petition of NGO All India Drug Action Network [12]. The inter-ministerial committee, particularly in the market-based pricing formula, examines the pricing of medicines [12]. This committee comprises representatives from DIPP (Department of Industrial Policy and Promotion), Ministry of Health, NNPPA, and Department of Pharmaceuticals (DoP) [12]. According to NGO ("All India Drug Action Network"), market-based pricing made the pricing of the medicines costlier than for any price control purposes. Prices of the drugs meant for lifesaving diseases such as diabetes and tuberculosis need to be included in the government regulatory price list. Under this new policy, simple average "Ceiling Prices," in many cases, are higher than the market leader price, according to NGO and the profit margin for pharma companies and dealers has become in

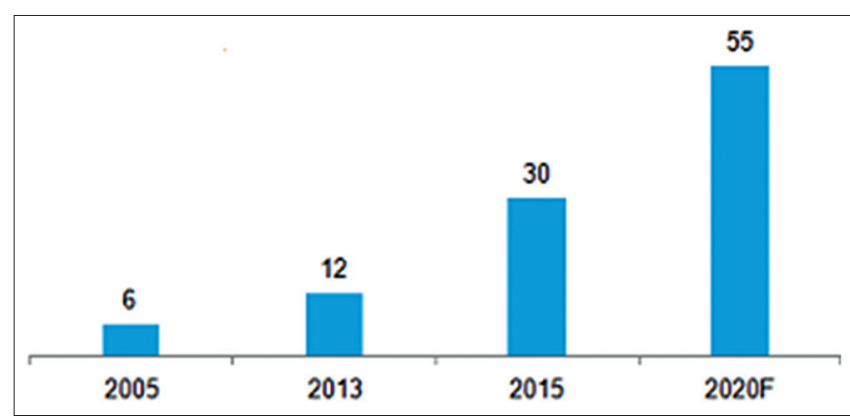

Fig. 1: Revenue of Indian Pharmaceutical Sector (US \$ billion) Source: Department of Pharmaceuticals, PWC, McKinsey, TechSci Research. F: Forecast, CAGR: Compound Annual growth rate. http://www.ibef.org/industry/pharmaceutical-india.aspx referred on 11/05/16

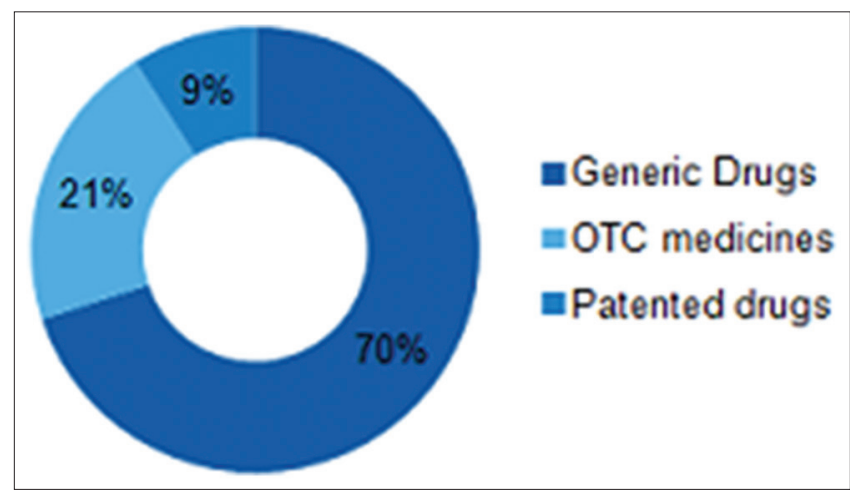

Fig. 2: Revenue share of Indian pharmaceutical sub-segments in $2015(\%)$

Source: Business Monitor International, FCCI Indian Pharma Summit 2014-15, TechSci Research. http://www.ibef.org/ industry/pharmaceutical-india.aspx referred on 11/05/16

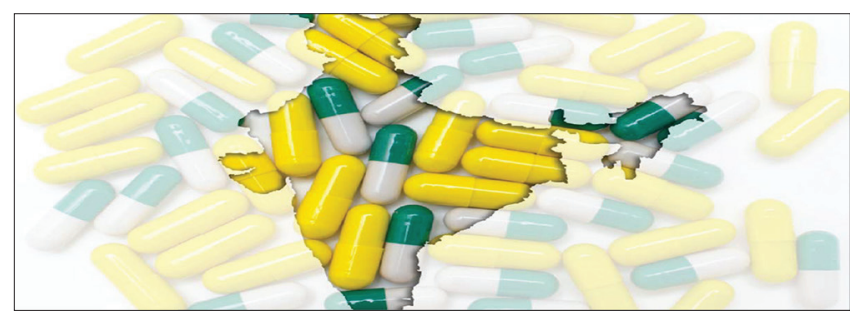

Fig. 3: Drugs in India

Source: Ram Subramanian et al., April 2014, https://www. simon-kucher.com/sites/default/files/are_market-based_ pharmaceutical_price_controls_the_new_reality_in_india_simonkucher_april_2014.pdf

the range of $10-1300 \%$ [13]. The NGO required a direction to the government to carry on with earlier "cost-based pricing" to arrive at "ceiling prices" for all essential drugs [13]. Drug price regulator NPPA fixes the ceiling price of essential medicines of schedule-1, as stipulated under DPCO 2013 [14]. The authority fixed the ceiling price of 530 formulations from the list and no one is authorized to sell any scheduled medicine to a consumer at a price higher than the one notified by NPPA under the order [14].

To ensure the availability of the scheduled bulk drugs at a fair price from different manufacturers, prices are fixed by the NPPA as per par 3 
of DPCO, 1995 and also prices are fixed from time to time by notification in official Gazette [15]. Steps such as "Identification of bulk drugs, collection of data, preparation of actual cost statement, preparation of technical parameters, preparation of estimated cost, calculation of fair price of bulk drug, fixation of maximum sale price of the drug, and notification of bulk drug price in official Gazette" are involved in fixation/revision of bulk drug prices [15]. Applications received in NPPA from manufacturers in Form III and importers in Form IV of DPCO are considered for price fixation [15].

The retail prices of formulations are worked out as per the formula given in para 7 of DPCO, $1995 \mathrm{viz}$.

“R.P. $=[$ M.C.+C.C.+P.M.+P.C. $] \times[1+$ MAPE $/ 100]+$ E.D."

Where, RP: Retail price stands for - RP, MC: Material cost, CC: Conversion cost, PM: Packaging material cost, PC: Packaging charges, MAPE: Maximum allowable post-manufacturing expenses, and ED: Excise duty stands for ED [15].

Market-based pricing is defined as a process of setting prices of goods/services based on the current market conditions, and prices are set according to mutual decision between sellers and buyers [28]. DPCO released by the India's DoP in May 2013, increased the number of essential medicines on the NLEM, and offered a new idea for determining and implementing the price ceilings while preserving the constant supply of drug [17]. Drugs in India are given in Figure 3.

The three main aims of DPCO are expanding the NLEM, authorizing the NPPA to control prices of India's NLEM, and authorizing the NPPA to control price increases of non-essential medicines [17]. There were 348 medicines listed in NLEM 2011 which now contains a total of 376 medicines in NLEM 2015 [18]. NPPA in India exempted drugmaker Wockhardt's three insulin products from price controls for 5 years from January 8, 2015, and Wockhardt had applied to the NPPA for non-application of the price control provisions [19]. The government issued a new DPCO which effectively brings close to 200 more drug formulations under regulation and NPPA mandated to fix or revise prices of controlled bulk drugs and formulations, and to enforce prices and availability of medicines in the country, beside monitoring prices of decontrolled drugs, to keep these at reasonable levels. Previously government added 106 and removed 70 medicines from earlier one of 2011 increasing the list to 376 from 348 [20]. India's drug pricing regulator NPPA was planning to coordinate with state governments across the country to combat overcharging by drug makers and also recently revised rates of several medications. NPPA fined nine drug firms with $\$ 372$ million for overcharging customers and also imposed a penalty after the drug makers, which included Ranbaxy, Dr. Reddy's, Glenmark, Cipla, and Cadila, were reportedly overcharging patients for doxofylline [21]. 277 medicines came under the regulation as per the new DPCO 2016, which was notified on March 2014 [22]. Indians were able to realize the reduction in their medical expenses due revised price of the drugs, and pharmaceutical companies are struggling to follow the new rule [22]. The new DPCO 2016, notified on March 14, which brought a total 277 medicines under the regulation [22]. From May 2016, Indians saw a sharp fall in their medical expenses as the revised price for all drugs came into effect even as pharma companies are struggling to comply with the new rule [22]. Ceiling price for the 103 drugs had been revised by NPPA for HIV/AIDS, bacterial infections, tuberculosis, high blood pressure, epilepsy, Hepatitis C, and Diabetes [22]. Because of the revised prices of NPPA, about 70 drugs would become cheaper, and NPPA retro pricing order has thrown the pharma industry in a tricky situation [22].

\section{CONCLUSION}

In India, prices of the medicines are controlled and price maximum for the essential medicines are set by the Indian government using DPCO. It is the responsibility of the government to safeguard the interest of pharma companies and also to ensure the availability of essential medicines at an affordable price to all sections of the society. To sustain and excel, pharmaceutical companies in India have to formulate strategy according to the policy of Indian government. Pharmaceutical companies can think of reducing the expenses to reduce the cost of drugs to comply with the government drug pricing policy. To ensure the affordability of medicines along with the pricing policy Indian government may look and concentrate on the other important areas of pharmaceutical sectors.

\section{REFERENCES}

1. Available from: http://www.ibef.org/industry/pharmaceutical-india. aspx. [Last referred on 2016 May 11].

2. April Maguire. 6 Different Pricing Strategies: Which is Right for Your Business? 2015. Available from: http://www.quickbooks.intuit.com/r/ pricing-strategy/6-different-pricing-strategies-which-is-right-for-yourbusiness/. [Last referred on 2016 May 11].

3. Rajagopal D. Policy bumps may hit pharmaceutical market's dream run. ET Bureau|22 Mar; 2016. The Economic Times. Available from: http://economictimes.indiatimes.com/industry/healthcare/ biotech/pharmaceuticals/policy-bumps-may-hit-pharmaceuticalmarkets-dream-run/articleshow/51504576.cms. [Last referred on 2016 May 11].

4. Fry E. Big pharma won't stay silent in drug pricing debate for long; 2015. Available from: http://www.fortune.com/2015/10/22/bigpharma-wont-stay-silent-in-drug-pricing-debate-for-long/.

5. Available from: http://www.ibef.org/industry/healthcare-india. aspx\#sthash.Heb8S1UI.dpuf. [Last referred on 2016 May 13].

6. Available from: http://www.ibef.org/industry/pharmaceuticalindia. aspx\#sthash.hSUomUqF.dpuf. [Last referred on 2016 May 13].

7. Available from: http://www.ibef.org/industry/pharmaceutical-india. aspx\#sthash.I1nbxhAO.dpuf. [Last referred on 2016 May 13].

8. Krishnan V, Mehra P. Intellectual property rights policy may hinder drug access. The Hindu dated May 13, 2016.

9. All you need to know about the new IPR Policy. The Hindu, dated May 14, 2016 IST. Available from: http://www.thehindu.com/business/ all-you-need-to-know-about-the-intellectual-property-rights-policy/ article8600530.ece.

10. Singh B. Message from Chairman, The National Pharmaceutical Pricing Authority (NPPA). Available from: http://www.nppaindia.nic. in/. [Last referred on 2016 May 13].

11. Available from: http://www.businessdictionary.com/definition/pricing. html. [Last referred on $2016 \mathrm{Apr} 08$ ].

12. Available from: http://www.thehindu.com/business/govt-formscommittee-to-review-drug-pricing-policy/article7830066.ece, 1/11/15. [Last referred on 2016 Apr 11].

13. Available from: http://www.tapanray.in/indias-drug-pricing-policyabsurd-unreasonable-and-irrational-supreme-court/. [Last referred on 2016 May 11].

14. Available from: http://www.thehindu.com/business/govt-formscommittee-to-review-drug-pricing-policy/article7830066.ece, 1/11/15. [Last referred on 2016 Apr 11].

15. Available from: http://www.nppaindia.nic.in/. [Last referred on 2016 Apr 11].

16. Available from: http://www.mbaskool.com/business-concepts/ marketing-and-strategy-terms/7285-market-based-pricing.html. [Last referred on 2016 May 27].

17. Subramanian R, Mutyal N, Nechamkin E. Are market-based pharmaceutical price controls the new reality in India? 2014. Available from: https://www.simon-kucher.com/sites/default/files/.

18. Available from: http://www.cdsco.nic.in/WriteReadData/NLEM-2015/ Recommendations.pdf. [Last referred on 2016 Apr 28]

19. Bureau ET|23 Nov, 2015, 06.21PM IST. Available from: http:// www.economictimes.indiatimes.com/industry/healthcare/ biotech/pharmaceuticals/national-pharmaceutical-pricing- 
authority-exempts-price-controls-for-3-insulins-of-wockhardt/ articleshow/49894230.cms.

20. About 200 more drugs under price control. Business Standard, BS Reporter|New Delhi, Mar 14, 2016. Available from: http://www. business standard.com/article/companies/about-200-more-drugsunder-price-control-116031401171_1.html.

21. The pharmaletter, India's NPPA brings many more drug formulations under price control, 15-03-2016. Available from: http:/www. thepharmaletter.com/article/india-s-nppa-brings-many-more-drugformulations-under-price-control.

22. Goyal A. NPPA caps prices of 48 more drugs, May 11, 2016 BTvIn.com. Available from: http://www.btvin.com/article/read/ industry/5649/nppa-caps-prices-of-48-more-drugs. [Last referred on 2016 Jul 09]. 